\title{
Pediculosis and the Pediatrician
}

\author{
James E. Rasmussen, M.D. \\ Professor of Dermatology and Pediatrics, University of Michigan Medical Center, \\ Department of Dermatology, Ann Arbor
}

\begin{abstract}
Head lice commonly evoke feelings of disgust, revulsion, anger, and shame among parents and patients. There should, however, be no great cause for such alarm if a physician suspects pediculosis capitis. The recent introduction of several new pediculicidal drugs now allows a choice among four distinct therapeutic agents, which should substantially improve control of isolated cases and epidemics. Physicians must be aware that consumer groups are pressing public health authorities and drug manufacturers to establish proper treatment standards and safety warnings for the use of these agents. In addition, some controversy surrounds the use of lindane in children. This paper reviews the epidemiology and clinical appearance of pediculosis capitis in children, with emphasis on these recent developments. Pubic lice (Phthirus pubis) and body lice (Pediculus humanus corporis), both of which are much less common pediatric infestations, are mentioned only briefly.
\end{abstract}

\section{EPIDEMIOLOGY}

Pediculosis capitis is caused by a 2 - to 4 -mm-long ivory-tan insect (Pediculus humanus capitis), which has in man its only natural host. Entomologists consider it a variant of the body louse, which it closely resembles physically (1). It is an obligate human parasite that cannot survive off its host for more than 10 days (adults) to 3 weeks (fertile eggs) under ideal conditions. Actual survival rates are probably much shorter than this. An adult female lays about six eggs per day that hatch in 8 to 10 days, with a fertility rate of $90 \%$. The eggs (nits) are cemented to the shaft of hairs, usually within $1 \mathrm{~cm}$ of the scalp. Fertile, unhatched nits fluoresce white with a Wood's lamp, while a gray color signifies empty eggs. There are usually fewer than two dozen active adults per patient.

The insect has a transient nymphal stage with a final metamorphosis into the characteristic cylindrical adult. Any of the three stages, adult, nymph, and egg, can be infectious, but most disease is transferred by adult organisms.

Pediculosis spreads easily through direct, personal contact or through fomites such as clothing (caps, hooded coats, ski masks, scarfs) or toilet articles (brushes, combs, towels). Early infestations are so mildly symptomatic that they may pass unnoticed by patient and parent until detected by a barber, beautician, or school nurse during a routine visit.

Because of their method of transmission, head lice are common in young school children, but prevalence can only be estimated since the disease is not usually reportable. Donaldson (2) in a 1975 survey among English children, estimated that 192,000 were infested $-2.4 \%$ of the school-age population

Address correspondence to: James E. Rasmussen, M.D., University of Michigan Hospitals, C-2069 Box 031, Ann Arbor, MI 48109-0010. 
in that country. Gratz (3) felt there were six million cases of head lice in the United States. Slonka et al (4) noted a prevalence of $3 \%$ among 1783 white pupils in a Georgia school system surveyed in 1976. Billstein and Laone (5) found 76 cases per 10,000 population in a lower socioeconomic group in Sacramento, California in 1979. Thus it is obvious that the problem is not a small one. My professional experience suggests that the number of new cases has increased substantially in the past five years.

Females are more commonly involved than males (6), but in some studies this difference is not apparent (7). Hair length is often the principal factor used to explain the higher number of females with head lice, but Slonka et al in two separate studies of head lice epidemics in western New York (6) and Georgia (4) could not demonstrate a significant association when analyzing these factors. Blacks are rarely infested, at least in the United States (4-6) but the reasons for this are unknown. One can speculate that the tighter hair spirals found commonly in blacks offer the lice a less suitable environment. Depending upon the epidemic, attack rates of $8 \%$ to $15 \%$ per year are not uncommon in the United States, and in some developing countries may reach $50 \%$. No age is immune, and local community practices such as prevalence of preschools do much to modify statistics. It is my experience that pediculosis capitis is most common in grades $K$ through 6 , but other statistics report higher rates in adults (8).

Prevalence of pediculosis is greatest in lower socioeconomic groups (4-6), where it is presumed that large family size, crowding, bed sharing, and lower standards of hygiene allow for more rapid transmission. Large epidemics, however, can be seen in public, private, and parochial schools in all sections of society. Sharing of school lockers and random use of coat hooks are important vectors in influencing the disease spread in schools.

\section{TREATMENT}

\section{General}

The general treatment of pediculosis capitis involves attempts to prevent its spread among exposed members of the family and others in the community. For isolated cases, it is probably enough to treat the patient and all members of the family. Parents should be strongly encouraged to contact school authorities to prevent epidemic spread among classmates. Once the problem becomes en- trenched in a school, more aggressive measures are necessary.

Communication with the parents of all schoolchildren is a must. The presence of the epidemic must be explained and suggestions made for selftreatment or referral to family physicians. The exact methods suggested depend upon the preferences of local authorities. Within the school itself, every effort must be made to control infection. Students and staff should know that sharing of hats, coats, scarfs, caps, combs, and towels is an important factor in the spread of this disease. Teachers should be given some common-sense education in how to screen the heads of children, for example, a frequent false positive finding is the small flakes of dandruff that commonly cling to the sides of hairs. These scales can easily be removed with very gentle traction. Nits, on the other hand, being cemented to the hair shaft, are not freely movable, but can be avulsed if traction is substantial.

In the home, all articles in contact with infected patient's scalp must be thoroughly washed or disinfected. Pillows, blankets, towels, caps, hoods, and the like can either be stored in plastic bags for approximately a month or washed. Combs, brushes, and other personal toilet articles are much more difficult to sterilize. Vigorous washing in hot, soapy water is probably adequate to remove most adult lice from these grooming aids. For those who feel the need to be more meticulous, a short soak (one hour) in rubbing alcohol is inexpensive, satisfactory, and safe. I do not suggest the use of microwave ovens to sterilize combs and brushes since most of these articles are made from plastic and frequently melt.

\section{Specific}

\section{$1 \%$ Lindane}

One percent lindane shampoo (Kwell, Scabene) is effective treatment for cases of pediculosis capitis, corporis, and pubis. The drug should be rubbed into the scalp of the patient and all family members, whether symptomatic or not, and allowed to remain for 10 minutes. Lindane cream or lotion is not necessary, but if it is used, the contact time should remain 10 minutes, not the 6 to 12 hours suggested in many references. Only the scalp need be treated in cases of pediculosis capitis.

There are several reports of the development of head lice resistant to lindane (9). These have only occurred in Europe where this agent is used in much lower concentrations than in the United 
States. It is not known if these lice are resistant to the $1 \%$ lindane currently in use in the United States.

Some individuals and consumer groups feel that lindane is not a safe pediculicide. A recent issue of Consumer Reports (10) summarized these arguments as (1) lindane is a toxic compound, (2) it is irritating, (3) it is a potential carcinogen, and (4) there are safer existing alternatives. For an in-depth discussion of these problems, the reader is referred to two recent reviews $(11,12)$.

The above points should be placed in the appropriate context. First, there is no question that lindane can be toxic if misused or ingested. It is important that patients and their parents be fully informed that lindane should be applied once and not repeated within a week. If such instructions are followed, there should be no toxic reactions. This is based on the fact that lindane has been used for 20 years and over $\mathbf{2 0}$ million doses have been sold for the treatment of head lice. During this time, Kramer et al $(13,14)$ found that there were no convulsions following the proper use of lindane for the treatment of head lice. Almost all reports of toxicity have come from ingestion or prolonged administration for the treatment of scabies.

There is no doubt that the drug is absorbed; however, this is true for all agents applied to the skin. Ginsburg et al studied the absorption of lindane in young patients with head lice (15) and with scabies (16). Patients with head lice had approximately onethirtieth the blood level of those with scabies $(0.96$ $\mathrm{ng} / \mathrm{ml}$ mean peak blood level vs $28 \mathrm{ng} / \mathrm{ml}$ ).

Second, mild irritation can occur with the use of lindane and all other pediculicides, particularly if excoriation and infection are present. All specific pediculicides are irritating to mucous membranes such as the eyes.

Third, in chronic high-dose animal feeding studies, lindane has been shown to be a possible carcinogen (see Rasmussen [10] for a general review). It produced hepatomas in one species in laboratory animals, but not in several others. These results were obtained after long-term high-dose feeding studies that produced substantial (20\% to $25 \%$ ) animal mortality from other causes. To gain the same exposure, a person would have to ingest a 30 $\mathrm{gm}$ tube of $\mathrm{Kwell}$ ( $1 \%$ lindane) on a daily basis from age 1 year through age 50 . Several other feeding studies at lower doses, as well as several skin painting studies, have not shown a carcinogenic effect. Those who believe that lindane is a carcinogen should also appreciate that several other agents used for the treatment of head lice are available in a form that consists in part of petroleum distillates, which, so evidence suggests, are also potentially carcinogenic (17). Regardless of these points of view, it is very unlikely that a single or even several applications applied to a small area of the body such as the scalp would cause any significant carcinogenesis. This position is also supported by the Consumers Reports article.

Finally, the safety and efficacy of the alternate scabicides have not been studied nearly as extensively as lindane. Lindane is sold over the counter in several major countries such as Canada. Reports of serious toxicity from its application in treatment of head lice are nonexistent in these areas. Given the freedom to abuse the drug that comes with overthe-counter use, this suggests that the potential for toxicity following the treatment of head lice is extremely small.

\section{Pyrethrins}

Pyrethrins are extracts from the flowers of members of the chrysanthemum family. Pyrethrins are usually used in combination with piperonyl butoxide, an agent that in some way enhances the effectiveness of the pyrethrin as an insecticide. Most of these products, such as Rid, A-200, and others, are contained in a vehicle that consists of petroleum distillates such as kerosene. Consequently, these agents can be irritating, particularly if they contact mucous membranes. Pyrethrins have been well studied in the treatment of pediculosis.

Smith and Walsh (18) conducted an open study comparing the efficacy of lindane shampoo with the over-the-counter pyrethrin-based pediculocide, Rid. The study was conducted in a group of $\mathbf{3 0}$ adults with pubic lice who were randomly assigned treatment with one of the two test agents. Both groups were treated with a single 5- to 10-minute application and returned in one week to ascertain the presence of active disease. The results showed lindane and pyrethrin products to be equally effective - all 30 patients were totally free of active disease. Newsom, Fiore, and Hackett (19) conducted a similar study of 30 adults with pubic lice. Patients were randomly assigned treatment with either a 0.3\% pyrethrin-3.0\% piperonyl butoxide lotion (Rid) or a $1 \%$ lindane lotion (Kwell). The pyrethrin mixture was given in a single 10-minute application and the lindane was used for a 12-hour application. A follow-up visit a week after treatment verified that all patients were cured. Lange et al (20) treated 
112 patients with a shampoo containing pyrethrins. All were given a single 10-minute application and followed up at one week for the presence of live lice. Only six patients had live lice immediately before the second treatment. Following the second treatment, no patient had live lice. Robinson and Shepherd (21) conducted a random study of synergized pyrethrins compared to lindane in the treatment of 26 children between the ages of 7 and 10 years with head lice. These authors used three consecutive weekly applications, and reported that both agents were equally effective.

All of these studies indicate that pyrethrins and lindane are effective in the treatment of head and pubic lice but no controls exist that separate the effectiveness of drug from vehicle. As a further advantage, many pyrethrin products are sold with a plastic nit comb, which has recently been redesigned to increase efficacy. Even more effective metal nit combs can be purchased separately as the Medi Comb (Nitex Labs, Boston, MA), Derboc Comb (Johnson Manufacturing, Boonton, NJ), or Innomed Comb (Innomed Inc., Greenwich, CT). While no known comb will remove all nits, the closely spaced teeth do assist in removing this bothersome sign of pediculosis capitis.

\section{$0.5 \%$ Malathion}

Taplin et al (22) evaluated the efficacy of $0.5 \%$ malathion lotion (Prioderm) in the treatment of subjects with head lice. They conducted a doubleblind, controlled study of 115 subjects (mean age 9 years) who used either $0.5 \%$ malathion lotion or its vehicle to treat active head lice. Both preparations were allowed to remain on the hair for 12 hours. Patients were evaluated at the end of a week, at which time there was a cure rate of $95.4 \%(62 / 65)$ for the active agent and $15 \%$ for the vehicle, a statistically significant difference $(P<0.001)$.

This study indicates that $0.5 \%$ malathion lotion is an effective agent for the treatment of pediculosis capitis and it is quite probable that the same efficacy will also extend to pediculosis of the body and pubic region. A long contact time (12 hours) represents one minor disadvantage of the use of malathion over some of the other agents. Shorter contact times were not studied by this group and may be effective.

Malathion is an organic phosphate, and although these compounds are known to inhibit the enzyme acetylcholinesterase, their toxicity for humans appears to be quite minimal. Malathion is rapidly bro- ken down in humans, but gross contamination has been reported to cause symptoms of cholinergic toxicity (not from the application of this product, however).

\section{$10 \%$ Crotamiton}

Karacic and Yawalkar (23) treated 49 patients with pediculosis capitis using a $10 \%$ crotamiton lotion. The study population included 26 patients under 10 years of age. The lotion was rubbed into the scalp and left on for 24 hours, and the scalp was examined on the seventh posttreatment day. This single application cured pediculosis capitis in $96 \%$ of the 49 patients. In two patients, a second application was necessary.

A minor disadvantage of crotamiton lotion in the treatment of patients with pediculosis capitis is the long contact time required ( 24 hours). While shorter contact times may be effective, they were not studied by these authors.

Those concerned about the safety of lindane suggest crotamiton as a safe choice. Toxicity of this drug has not been as scrutinized as that of lindane because it is only used one-twenty-fifth as frequently. Safety and absorption of crotamiton in children, adults, and pregnant women have not been evaluated.

\section{Pediculosis of the Eyelashes}

Pediculosis of the eyelashes is not a common problem in children, but when it occurs, the responsible organism is the pubic rather than the head louse (24). Prepubertal children lack the appropriate pubic environment for crab lice, which are forced to take up residence in the next best terrain - the eyelashes. The diagnosis should be considered when a child complains of lid pruritus, scaling, crusting, or purulent discharge. The diagnosis can be made easily if the area is carefully examined with a strong light and preferably with a magnifying lens. If the clinical appearance is not obvious, a small set of smooth tweezers can be used to epilate eggs, organisms, or a few hairs for microscopic examination.

Lindane, pyrethrin, crotamiton, and malathion are far too irritating to be used on such a sensitive surface as the eyelids. There are, however, several other acceptable alternatives (25).

The treatment of choice for lice of the eyelashes is petrolatum (Vaseline). The ointment is rubbed on the eyelashes with a finger or cotton swab three to five times a day. The exact mechanism of action is 
uncertain, but the lice may either be suffocated or slip off and fall to their death. Obviously, a diligent search should be made for the presence of pubic lice within the family, and all infected or exposed adults treated appropriately from the neck down.

Physostigimine, $0.25 \%$ (Eserine) can also be applied to the eyelashes several times a day for three days. This agent is a pupillary constrictor, and consequently inhibits dark adaption. This appears to be its only major side effect.

Also potentially useful are fuorescein eye drops. Matthew et al (26) reported on their accidental observation that $20 \%$ fluorescein drops applied to the lids and lashes of a patient with phthiriasis palpebrarum produced an immediate toxic effect on the lice. The authors extended their observations to a small group of patients with head lice, reporting the most notable effects with $10 \%$ to $20 \%$ concentrations. The obvious disadvantage to this form of therapy is that it leaves an orange-green stain on the skin. It may, however, be useful for the patient who is unwilling or unable to use the other previously mentioned ingredients.

Yellow oxide of mercury, $0.1 \%$, is an outmoded treatment and the substance is difficult to obtain.

\section{SYSTEMIC THERAPY}

There are few situations in which one of the four preceding topical pediculicides is not effective. A rare patient may have severe matting of the hair and dense infestation that will not respond to topical agents. In this situation, only two choices remain shaving the scalp to remove the organisms physically or oral treatment with cotrimoxazole. Sashindran and associates (27) studied 20 female patients with pediculosis capitis. They were treated once or twice a day with one tablet of cotrimoxazole $(80 \mathrm{mg}$ trimethoprim plus $400 \mathrm{mg}$ sulfamethoxazole, - Bactrim or Septra) twice daily for three days. Within the next 12 to 48 hours, the lice migrated to the bed clothes and later died. Neither trimethoprim nor sulfamethoxazole showed any effect on the lice when used separately. Cotrimoxazole has no effect on nits, and consequently a second course of therapy must usually be given 7 to 10 days after the first. This regimen was used in Sashindran's patients and produced complete cures in all.

The reader should be aware that these agents will only rarely (if ever) be necessary in the treatment of pediculosis, and that their use can be associated with major side effects such as toxic epidermal necrolysis.

\section{PARENT SUPPORT GROUPS}

The National Pediculosis Association, (Post Office Box 149, Newton, MA 02161; telephone (617) 969 5623 ) is a common-interest group for parents. They provide a central depository of advice on control of school epidemics, and are an effective lobby for improved consumer labeling of over-the-counter and prescription pediculicides.

\section{REFERENCES}

1. Busvine JR. Pediculosis: biology of the parasites. Scabies and pediculosis. Philadelphia: JB Lippincott, 1977.

2. Donaldson RJ. The head louse in England, prevalence amongst schoolchildren. London: Health Education Council, U.K., 1975.

3. Gratz NG. The current status of louse infestations throughout the world. Proceedings of the International Symposium on the control of lice and louseborne diseases. Washington, DC: U.S. Government Printing Office, 1973:23-31.

4. Slonka GF, McKinley TW, McCroan JE, et al. Epidemiology of an outbreak of head lice in Georgia. Am J Trop Med Hyg 1976;25:739-743.

5. Billstein $S$, Laone P. Demographic study of head lice infestations in Sacramento County school children. Int J Dermatol 1979;18:301-304.

6. Slonka GF, Fleissner ML, Berlin J, et al. Recent insights into the childhood "social diseases" gonorrhea, scabies, pediculosis, pinworms. Clin Pediatr 1978;17:318-322.

7. Nitzkin JL. Pediculosis capitis. JAMA 1977;237:530532 .

8. Schenone H, Falah F, Villarroel F, et al. La infestacion por Pediculus humanus capitis en Santiago de Chile. Bol Chil Parasitol 1972;28:783-788.

9. Maunder JW. Use of malathion in the treatment of lousy children. Community Med 1971;126:145-147.

10. Remedy for head lice may be too strong a cure. Consumer Reports 1983;48(8):385.

11. Rasmussen JE. The problem of lindane. J Am Acad Dermatol 1981;5:507-516.

12. Shacter B. Treatment of scabies and pediculosis with lindane preparations: an evaluation. J Am Acad Dermatol 1981;5:517-527.

13. Kramer MS. Operational criteria for adverse drug reactions: an updated evaluation of $1 \%$ gamma benzene hexachloride. Drug Informational J 1982; JulySeptember;6:140-144.

14. Mcllreath F. Reed \& Carnrick Pharmaceuticals. Personal communication, May 19, 1983.

15. Ginsburg CM, Lowry W. Absorption of gamma benzene hexachloride following application of Kwell shampoo. Pediatr Dermatol 1983;1:74-76.

16. Ginsburg CM, Lowry W, Reisch JS. Absorption of lindane (gamma benzene hexachloride) in infants and children. J Pediatr 1977;91:998-1000.

17. Garmon L. Rodent test links gasoline, kidney cancer. Science News 1983;123(23):359. 
18. Smith DE, Walsh J. Treatment of pubic lice infection: a comparison of two agents. Cutis 1980;26:618-619.

19. Newsom JH, Fiore JL, Hackett E. Treatment of infestation with Phthirus pubis: comparative efficacies of synergized pyrethrins and gamma benzene hexachloride. Sex Transm Dis 1979;6:196-201.

20. Lange $K$, Nielsen AO, Jensen $O$, Graudal $C$. Pyriderm shampoo in the treatment of pediculosis capitis. Acta Derm Venereol 1980;61:91-92.

21. Robinson DH, Shepherd DA. Control of head lice in schoolchildren. Curr Therap Res 1980;27:1-6.

22. Taplin D, Castillero PM, Spiegel J, et al. Malathion for treatment of Pediculus humanus var capitis infestation. JAMA 1982;247:3103-3105.
23. Karacic I, Yawalkar SJ. A single application of crotamiton lotion in the treatment of patients with pediculosis capitis. Int J Dermatol 1982;21:611-613.

24. Alexander JO. Phthirus pubis infestation of the eyelashes. JAMA 1983;250:32.

25. Couch JM, Green WR, Hirst LW, De La Cruz BS. Diagnosing and treating Phthirus pubis paipebrarum. Surv Ophthalmol 1982;26:219-225.

26. Matthew M, DiSouza P, Mehta DK. A new treatment of phthiriasis palpebrarum. Ann Ophthalmol 1982; 14:439-441.

27. Shashindran CH, Gandhi IS, Krishnasamy S, Ghosh MN. Oral therapy of pediculosis capitis with cotrimoxazole. Br J Dermatol 1978;98:699-700. 
This document is a scanned copy of a printed document. No warranty is given about the accuracy of the copy. Users should refer to the original published version of the material. 